\title{
Cervical leiomyoma: a rare case with unusual presentation
}

\author{
Shamrao Ramji Wakode, Roshni Vinod Lodha*
}

Department of Gynecology and Obstetrics, Dr. SCGMC, Nanded, Maharashtra, India

Received: 29 October 2021

Accepted: 04 December 2021

\author{
*Correspondence: \\ Dr. Roshni Vinod Lodha, \\ E-mail: Roshnilodha72@gmail.com
}

Copyright: () the author(s), publisher and licensee Medip Academy. This is an open-access article distributed under the terms of the Creative Commons Attribution Non-Commercial License, which permits unrestricted non-commercial use, distribution, and reproduction in any medium, provided the original work is properly cited.

\begin{abstract}
Leiomyomas or fibroids are the most common benign pelvic tumors in females that grow mono-clonally from the smooth muscle cells of the uterus. Most common tumors of the uterus are fibroids but cervical fibroid is rare during pregnancy with different management difficulties but cervical leiomyomas are less than $5 \%$ of all leiomyomas. A middle-aged female patient came to the obstetric opd with complaints of amenorrea for 2 months, per vaginal spotting and abdominal pain for 5 days. Her obstetric score is gravida 2 para 1 living 1 . She has no h/o of urinary retention, urgency, constipation or mass per vagina. There is no history of bleeding during coitus. This case is of great importance not only because of its atypical presentation, but because we are dealing with rare pathology that can have consequences as serious as a total uterine inversion or a complete uterovaginal prolapse. Decision of myomectomy SOS hysterectomy may be considered intra operatively based on 1. Age, 2. Parity, 3. Severity of symptoms and 4. Experience of surgeon
\end{abstract}

Keywords: Cervical fibroid, Unusual presentation, Myomectomy

\section{INTRODUCTION}

Leiomyomas or fibroids are the most common benign pelvic tumors in females that grow mono-clonally from the smooth muscle cells of the uterus. Such tumors occur in nearly half of women over the age of 35 years, with increased prevalence during the reproductive phase due to hormone-stimulated growth. ${ }^{1}$

Most common tumors of the uterus are fibroids but cervical fibroid is rare during pregnancy with different management difficulties but cervical leiomyomas are less than $5 \%$ of all leiomyomas. ${ }^{2}$

Fibroids affect fertility, and can have severe psychological impact on a woman's life with continued growth, myomas can cause compression-related symptoms, such as dyspnea, frequent urination, or bowel complaints. ${ }^{3,4}$

\section{CASE REPORT}

A middle-aged female patient came to the obstetric OPD with complaints of amenorrea since 2 months, per vaginal spotting and abdominal pain since 5 days. Her obstetric score is gravida 2 para 1 living 1 . She has no h/o of urinary retention, urgency, constipation or mass per vagina. There is no history of bleeding during coitus.

Menarche occurred at 14 years of age, and her menstrual periods had always been regular with average flow. Last menstrual period: patient as no information.

She denied currently taking oral contraceptives. there is no significant medical and surgical history. The remainder of the patient's history, including a focused family history, was non-contributory.

A 36 years old patient moderately built and nourished conscious and oriented. The patient's vital signs showed blood pressure of $121 / 76 \mathrm{mmHg}$, heart rate of $70 / \mathrm{min}$, respiratory rate of $15 / \mathrm{min}$ and oral temperature of $36.7^{\circ} \mathrm{C}$; her oxygen saturation was $100 \%$ on room air.

Her physical examination showed mild pallor. Her lower abdominal area was tense, with no evidence of ascites or hepatosplenomegaly. A mass of 14-16 weeks size gravid 
uterus, firm in consistency, non-tender with restricted mobility was noted. Lower margin could not be reached.

Chest examination showed normal vesicular breathing bilaterally with no adventitious sounds. The rest of examination including heart and neurological system was unremarkable.

Per speculum examination showed lateralised cervical OS, a large solid mass arising from the anterior lip of cervix with minimal bleeding through cervical OS.

Bimanual examination showed a large solid mass filling pelvic cavity. Uterus could not be felt AS separate entity.

Laboratory analysis showed a blood haemoglobin concentration of $8 \mathrm{~g} / \mathrm{dL}$. The remainder of her laboratory results were within physiological parameters. UPT: positive transabdominal ultrasonography revealed bulky uterus with retained product of conception, large uterine myoma of $11 \times 12 \times 12 \mathrm{~cm}$. Neither ascites nor hydronephrosis was noted. The patient was counselled about the diagnosis of uterine fibroid, after proper counselling and written informed consent patient was taken up for the proposed procedure.

Patient underwent manual vacuum aspiration for retained products of conception. A month later she was planned for proposed procedure.

Intraoperatively, the uterus was grossly enlarged by a large fibroid measuring $11 \times 12 \times 12 \mathrm{~cm}$. Both ovaries and fallopian tubes were normal. The uterus was elevated out of the abdominal cavity and myomectomy of the large tumour was achieved through a lower segment incision. The excision site was closed with continuous vicryl sutures, and the uterus was reconstructed and the abdomen was closed in layers. Cut section of the gross specimen revealed whitish nodules with a whorled appearance with fibroelastic consistency suggestive of benign leiomyoma. The specimen was sent for formal histopathology. Results of histopathological examination confirmed the diagnosis of a benign fibroid of the uterus.

The patient's post-op course was uneventful, and she was discharged on postop day seven. A 6 month follow-up with repeat USG arranged. Counselling regarding recurrence and future fertility was offered before discharge.

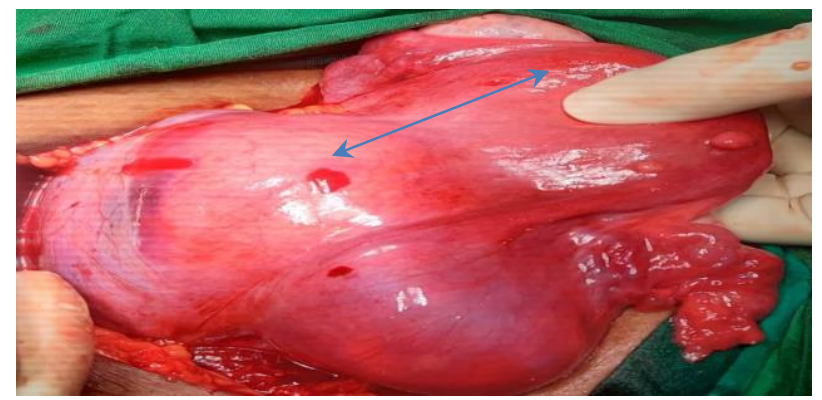

Figure 1: Fibroid uterus at the cervical region.

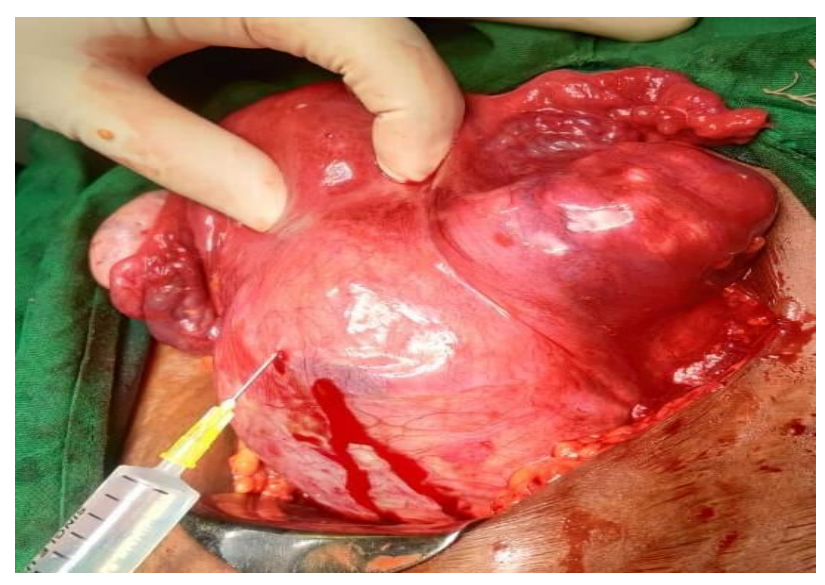

Figure 2: Infiltration of LA and adrenaline.

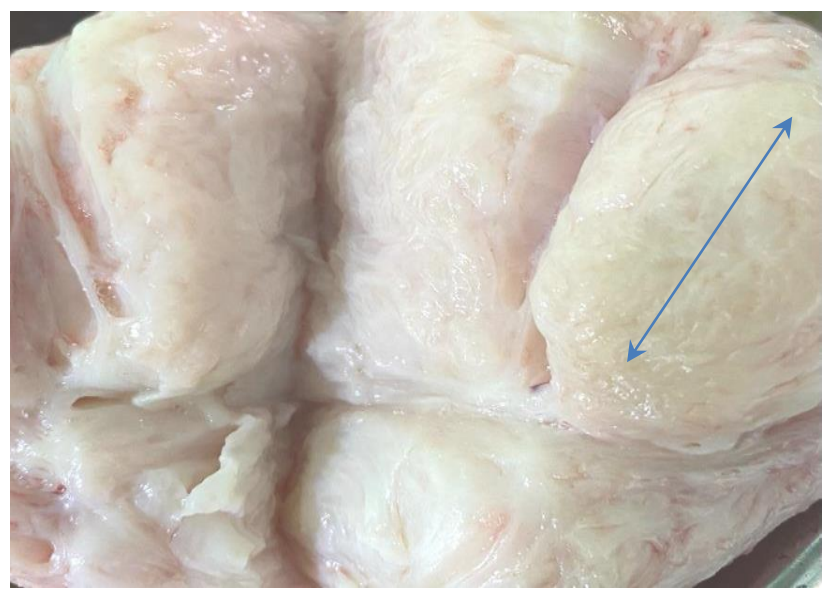

Figure 3: Cut section of uterus of whorled appearance.

She was offered family planning counselling and advised not to conceive for at least one year to allow wound healing and full recovery.

\section{DISCUSSION}

leiomyomas are known to grow in response to both oestrogen and progesterone stimulation, and their prevalence increases throughout the reproductive years and is markedly reduced after menopause. As many consultants may consider this fibroid of size 12-14 weeks for hysterectomy as a definitive line of management but the patient from the reproductive young age group (aged 36 years) we had planned myomectomy for this patient and SOS if required hysterectomy.

The presence of an isolated cervical fibroid is very rare, and its incidence is reported in $0.6 \%$ of the hysterectomies. ${ }^{2,5}$

There are very few cases of large cervical fibroids reported in literature. Excessive growths in cervical fibroids are rare. They generally present with symptoms of pressure 
effects however; in this case the patient was largely asymptomatic.

Cervical myomas can be classified into sub-serosal and intramural. Cervical fibroids may also be classified as: anterior, posterior, lateral central and lastly multiple. The symptoms of cervical fibroid depend upon the type of cervical fibroid. Anterior fibroid bulges forward and undermines the bladder while posterior flattens the pouch of Douglas backwards, compressing rectum against sacrum. Lateral cervical fibroid, starting on the side of the cervix burrows out into the broad ligament and expands it. Their relation to the ureter is important. Wherever the ureter and uterine artery may be in relation to the fibroid, they will always be extracapsular. ${ }^{6}$ The knowledge of this fact can turn potentially dangerous procedure into a relatively safe operation.

Central cervical fibroid expands the cervix equally in all directions. Upon opening the abdominal cavity, a central cervical myoma can be recognized at once because the cavity of the pelvis is more or less filled by a tumour, elevated on the top of which is the uterus like "the lantern on the top of St Paul's. ${ }^{6}$ Kavitha et al reported a case of large central cervical fibroid with typical "Lantern on top of St. Paul" appearance. ${ }^{7}$

During evacuation of the uterus, cervical dilatation is important as instrumentation is required to allow passage of contents with reduced cervical trauma and to minimize risk of retained tissue. ${ }^{8}$ Indeed, fibroids can impede this passage and, at term, delivery sometimes necessitates hysterotomy. An obstructive cervical fibroid is a known indication for operative term delivery via caesarean section. ${ }^{9}$ There are case reports of cervical fibroid posing issues in peripartum care at or near term. ${ }^{10,11}$ However, there is little literature on the management of elective termination for pregnancies complicated by cervical fibroid.

Surgical treatments such as myomectomy, myolysis, and hysterectomy can be employed when appropriate. Myomectomy is a common procedure performed for young women with symptomatic leiomyomas; it preserves fertility, does not interfere with the hormonal milieu of the developing adolescent, and is associated with a low recurrence rate. ${ }^{12}$

\section{CONCLUSION}

This case is of great importance not only because of its atypical presentation, but because we are dealing with a rare pathology that can have consequences as serious as a total uterine inversion or a complete uterovaginal prolapse.

The advantage of transverse incision is that it can be placed well above the level of bladder reflection and so reduce the risk of bladder damage. The disadvantage is that it cuts across vessels, which results in increased haemorrhage.
Physicians should offer pre- and post-procedure counselling regarding future fertility, recurrence following treatment, family planning options, and the importance of early and frequent antenatal visits when pregnant, as well as early completion of family size.

A high degree of suspicion is important when encountering a young woman with a pelvic mass. Pelvic examination and ultrasonography are crucial to establish the diagnosis.

Thus, we conclude that myomectomy is the best procedure, in view of preserving fertility. The knowledge of the altered anatomical structures is important while performing surgeries for cervical fibroid.

Decision of myomectomy SOS hysterectomy may be considered intra operatively based on 1. Age, 2. Parity, 3. Severity of symptoms and 4. Experience of surgeon.

Funding: No funding sources

Conflict of interest: None declared

Ethical approval: Not required

\section{REFERENCES}

1. Al-Hendy A, Myers ER, Stewart E. Uterine fibroids: burden and unmet medical need. Semin Reprod Med. 2017;35(6):473-80.

2. Buttram VC Jr, Reiter RC. Uterine leiomyomata: etiology, symptomatology,and management. Fertil Steril. 1981;36(4):433-45.

3. Whynott RM, Vaught KCC, Segars JH. The effect of uterine fibroids on infertility:a systematic review. Semin Reprod Med. 2017;35(6):523-32.

4. Zimmermann A. Prevalence, symptoms and management of uterine fibroids: an international internet-based survey of 21,746 women. BMC Womens Health. 2012;12:6.

5. Tiltman AJ. Leiomyomas of the uterine cervix: a study of frequency. Int $\mathbf{J}$ Gynecol Pathol. 1998;17(3):231-4.

6. Monaghan JM, Lopes AB, Naik R. Total hysterectomy for cervical and broad ligament fibroids. In: Huxley R, Taylor S, Chandler K, eds. Bonney's Gynaecological Surgery. $10^{\text {th }}$ ed. Maiden, USA: Blackwell Publishing Company. 2004;74-86.

7. Kavitha B, Jyothi R, Rama DA, Madhuri K, Sachin A, Murthy SG. A rare case of central cervical fibroid with characteristic Lantern on top of st. paul appearance. Int J Res Dev Health. 2014;2(1):45-7.

8. Autry AM, Hayes EC, Jacobson GF, Kirby RS. A comparison of medical induction and dilation and evacuation for second-trimester abortion. Am J Obstetr Gynecol. 2002;187(2):393-7.

9. James D, Steer PJ, Weiner CP, Gonik B. High Risk Pregnancy: management Options, Cambridge University Press,New York, NY, USA. 2017;5. 
10. Gandhi A, Dugad HI, Shah Y. A rare presentation of cervical fibroid in pregnancy. Ann Afr Med. 2014;13(2):88.

11. Sengupta S, Reddy K, Pillai M. Prolapsed cervical fibroid in pregnancy: A challenging obstetric dilemma. J Obstetr Gynaecol. 2009;26(8):823-4.

12. Moroni RM, Vieira CS, Ferriani RA, Reis RM, Nogueira AA, Brito LG. Presentation and treatment of uterine leiomyoma in adolescence:a systematic review. BMC Womens Health. 2015;15:4.
13. Swati S, Chaudhary P. Central cervical fibroid mimicking as chronic uterine inversion. Int $\mathbf{J}$ Reproduct Contracept Obstet Gynaecol. 2013;2(4):687-8.

Cite this article as: Wakode SR, Lodha RV. Cervical leiomyoma: a rare case with unusual presentation. Int J Reprod Contracept Obstet Gynecol 2022;11:275-8. 